\title{
KARAKTERISASI PASTA GIGI BERBAHAN ABRASIF HIDROKSIAPATIT (HAp)
}

\author{
Agung Rimayanto Gintu ${ }^{a}$, Elizabeth Betty Elok Kristiani ${ }^{b}$,Yohanes Martono ${ }^{c}$ \\ ${ }^{a}$ Magister Biologi, Fakultas Biologi, Universitas Kristen Satya Wacana, Jln Diponegoro No.52-60 Salatiga (50711) \\ Jawa Tengah \\ ${ }^{b}$ Fakultas Biologi, Universitas Kristen Satya Wacana, Jln Diponegoro No.52-60 Salatiga (50711) Jawa Tengah \\ ${ }^{c}$ Fakultas Sains dan Matematika, Universitas Kristen Satya Wacana Jln Diponegoro No.52-60 Salatiga (50711) Jawa \\ Tengah \\ email: agunggintu911@gmail.com; agunggintu911@yahoo.com
}

Received 8 October 2020 Accepted 5 December 2020

\begin{abstract}
Abstrak
Pasta gigi merupakan suatu sediaan untuk perawatan gigi untuk mebersihan, memperindah serta mengganti mineral yang meluruh dari permukaan gigi. Untuk mencegah kerusakan lapisan mineral pada gigi, dilakukan penambahan komponen remineralisasi berupa $\mathrm{CaCO}_{3}, \mathrm{CaPO}_{4}$ bahkan nano kalsium seperti Hidroksiapatit (HAp). Pada penelitian ini dihasilkan pasta gigi berbahan abrasive HAp dan $\mathrm{CaCO}_{3}$ dengan rasio campuran $\mathrm{CaCO}_{3}, 50: 50$ (HAp: $\mathrm{CaCO}_{3}$ ) dan HAp. Hasil karakterisasi menunjukkan pada pasta gigi berbahan abrasive $\mathrm{CaCO}_{3}$ menunjukkan kadar Kalsium

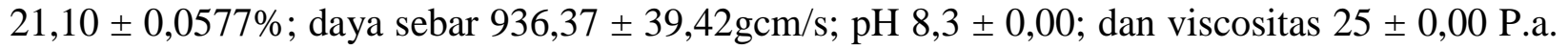
Hasil karakterisasi menunjukkan pada pasta gigi berbahan abrasive 50:50 ( $\mathrm{HAp}: \mathrm{CaCO}_{3}$ )

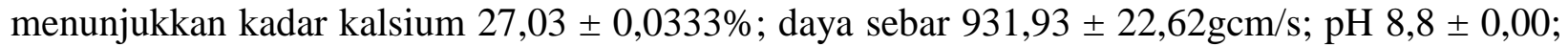
dan viscositas $27 \pm 0,00$ P.a. Hasil karakterisasi menunjukkan pada pasta gigi berbahan abrasive HAp menunjukkan kadar kalsium 27,67 $\pm 0,0882 \%$; daya sebar 987,33 $\pm 39,50 \mathrm{gcm} / \mathrm{s} ; \mathrm{pH} 8,9 \pm$ 0,00; dan viscositas 27,5 $\pm 0,00$ P.a. Tidak ditemukan adanya cemaran mikroba pada semua sediaan pasta gigi selama masa penyimpanan. Berdasarkan uji organoleptic secara menyeluruh terhadap pasta gigi, pasta gigi berbahan abrasive campuran $\mathrm{HAp}: \mathrm{CaCO}_{3}$ kurang disukai.
\end{abstract}

Kata kunci: Hidroksiapatit, Gigi, Kalsium

\begin{abstract}
Tootpaste was a product for dental care to clean, beautify and replace the minerals decay from the dent surface. To prevent the damage of the mineral layers on the surface, added the remineralitation compounds like $\mathrm{CaCO}_{3}, \mathrm{CaPO}_{4}$, also calcium in nano size like Hydroxyapatite (HAp). In this study produced the contains abrasive $\mathrm{HAp}$ and $\mathrm{CaCO}_{3}$ with the mix ratio $\mathrm{CaCO}_{3}, 50: 50$ (HAp: $\mathrm{CaCO}_{3}$ ) and HAp. The characterization to the toothpaste with $\mathrm{CaCO}_{3}$ abrasive showed the Calcium

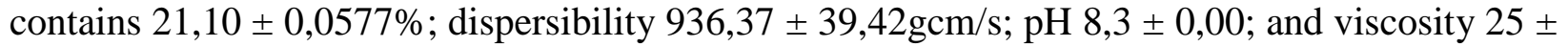
0,00 P.a. The toothpaste with $\mathrm{CaCO}_{3}: \mathrm{HAp} \mathrm{(50:50)}$ abrasive showed the Calcium contains 27,03 \pm $0,0333 \%$; dispersibility $931,93 \pm 22,62 \mathrm{gcm} / \mathrm{s} ; \mathrm{pH} 8,8 \pm 0,00$; and viscosity $27 \pm 0,00$ P.a. The toothpaste with HAp abrasive showed the Calcium contains 27,67 $\pm 0,0882 \%$; dispersibility $987,33 \pm 39,50 \mathrm{gcm} / \mathrm{s} ; \mathrm{pH} 8,9 \pm 0,00$; and viscosity $27,5 \pm 0,00$ P.a. The contamination of microbiology did not found in all of the toothpastes along the storage. Based on the entire organoleptic test against the toothpastes, the formula of toothpaste with the mix of $\mathrm{CaCO}_{3}: \mathrm{HAp}$ was les liked.
\end{abstract}

Keywords: Calcium, Hydroxyapatite, Tooth. 


\section{Pendahuluan}

Komponen utama penyusun pasta gigi pada umumnya mengandung komponen abrasif sebagai antiplak dan stain, flour untuk ketahanan gigi dan mencegah karies (Pramana, 2014). Salah satu komponen pasta gigi yang disarankan adalah mengandung flour yang sangat efektif melindungi gigi secara permanen dari karies, namun penggunaannya yang berlebihan dalam jangka waktu yang panjang dapat menyebabkan fluorosis pada gigi (Putri et al, 2015). Prinsip kerja utama pasta gigi terfokus pada dua parameter, yang pertama mengurangi plak dan karies gigi yang dihasilkan oleh aktivitas mikroba, dan yang kedua membantu remineralisasi enamel gigi karena banyak mineral pelindung enamel gigi yang tereduksi akibat aktivitas bakteri rongga mulut (Maldupa et al, 2012). Penelitian sebelumnya melaporkan bahwa, penambahan kalsium karbonat dalam formula pasta gigi yang optimal adalah 40g (Rahman, 2009) sehingga dilakukan optimasi kemampuan daya antibakteri HAp. Daya antibakteri pada dosis terendah akan diaplikasikan dalam formula pasta gigi sebagai agensia antibakteri karies (Wadu et al, 2017; Wadu et al, 2018). Syarat mutu pasta gigi dapat dilihat pada Tabel 1.

Tabel 1. Syarat mutu pasta gigi (Burhanuddin, 2014; Sandi, 2012; SNI 12-3524-1995)

\begin{tabular}{llll}
\hline No. & Jenis Uji & Satuan & Syarat \\
\hline 1 & $\mathrm{pH}$ & - & $4,5-10,5$ \\
\hline 2 & Cemaran logam : & & \\
& $\mathrm{Pb}$ & $\mathrm{ppm}$ & Maksimal 5,0 \\
& $\mathrm{Hg}$ & $\mathrm{ppm}$ & Maksimal 0,02 \\
& $\mathrm{As}$ & $\mathrm{ppm}$ & Maksimal 2,0 \\
& Campuran mikroba : & & \\
\hline 3 & Angka lempeng total & - & $<10^{5}$ \\
& E. coli & - & Negatif \\
\hline 4 & Zat pengawet & - & Sesuai yang diijinkan DepKes \\
\hline 5 & Zat pewarna & - & Sesuai yang diijinkan DepKes \\
\hline 6 & Organoleptik : & & \\
& Keadaan & - & Harus lembut, homogen, tidak terlihat \\
& Benda asing & - & adanya gelembung udara, tidak ada \\
& & & gumpalan dan tidak terdapat partikel \\
& & & yang terpisah. \\
& & & Tidak tampak \\
\hline
\end{tabular}

Karies gigi merupakan penyakit gigi dan mulut yang umum ditemui dalam masyarakat Indonesia. Karies gigi merupakan penyakit multifactorial yang penyebabnya didukung oleh faktor permukaan gigi, substrat, mikroorganisme dan waktu (Prasetya, 2008). Substrat yang menempel pada permukaan gigi memiliki sifat lebih lengket sehingga harus cepat dibersihkan dengan menyikat gigi. Substrat yang tidak dibersihkan dapat memicu pertumbuhan bakteri $S$. mutans dan $L$. acidophilus (Prasetya, 2008; Wadu et al,
2017). Penelitian sebelumnya terhadap anakanak karies dan non-karies melaporkan bahwa salah satu faktor yang dapat meningkatkan jumlah koloni dan aktivitas bakteri karies adalah minuman berkarbonasi yang rasanya manis dan bersifat asam (Prasetya, 2008; Pratama, 2014). Saliva manusia tidak memiliki kemampuan yang cukup untuk melakukan pembersihan gigi dari substrat yang menempel, menetralisir asam dan meminimalisir perkembangbiakan mikroba sehingga karies sangat berpotensi terbentuk ketika mengkonsumsi 
makanan/minuman dengan tingkat kemanisan dan kesaman tinggi. Secara kimiawi, karies terbentuk ketika suatu nutrient karbohidrat yang mengandung gugus sitrat (atau maleat dan tartrat) pada suasana asam mengerosi gigi dan membentuk garam kalsium sitrat kemudian terjadi pengikatan kembali membentuk kompleks garam kalsium yang menempel pada enamel gigi (Prasetya, 2008; Pratama, 2014).

Karies atau plak pada gigi merupakan hasil aktivitas enzimatis bakteri - bakteri yang berkembang biak di permukaan dan cela gigi akibat adanya substrat nutrisi (yang tidak bersih saat dibersihkan) terutama berasal dari sisa makanan. Karies memngakibatkan permukaan gigi yang dilekati menebal. Penebalan permukaan gigi ini diikuti dengan kerapuhan enamel gigi. Kerapuhan berkelanjutan mengakibatkan keroposnya gigi. Kerapuhan enamel gigi dipicu oleh asam yang dihasilkan oleh reaksi enzimatis bakteri karies yang menyebabkan merenggangnya jarak antar mineral penyusun enamel gigi kemudian mineral mineral tersebut terurai. Jika penguraian dan perenggangan mineral ini terus berlanjut maka mengakibatkan gigi berlubang. Selama ini, langkah yang digunakan untuk mengatasi bakteri karies adalah dengan menambahkan senyawa antibiotic dalam pasta gigi namun belum ada pasta gigi yang dapat melakukan remineralisasi kalsium pada bagian gigi yang dilekati karies (Prasetya, 2008; Pratama, 2014).

Pembentukan karies adalah hasil aktivitas dari beberapa bakteri yaitu Lactobacillus acidophilus, Streptococcus mutans, Actinomyces viscosus dan Nocardia $s p$. Penelitian sebelumnya menunjukkan bahwa hidroksiapatit menghasilkan aktivitas antibakteri yang kuat terhadap salah satu bakteri penyebab karies yaitu Lactobacillus acidophilus (Wadu et al, 2017). Penggunaan HAp sebagai bahan aktiv pasta gigi dimulai dari gagasan untuk menghasilkan bahan aktif dengan kerja ganda yaitu sebagai antibakteri sekaligus sebagai agen remineralisasi gigi (Wadu dkk, 2018).

\section{Metode Penelitian \\ Alat dan Bahan}

Alat yang digunakan dalam penelitian ini adalah $\mathrm{pH}$ meter, hot plate, incubator, neraca analitik 4 digit dan spatula. Piranti yang digunakan berupa Erlenmeyer, beaker glass, cawan petri, buret $50 \mathrm{ml}$, pipet ukur $10 \mathrm{ml}$ dan spatula. Bahan kimia yang digunakan erupa $\mathrm{CaCO}_{3}$ (P.A), Na-EDTA, indicator EBT, Buffer $\mathrm{PO}_{4} \mathrm{pH}$, medium NA, dan Na-CMC.

\section{Pengukuran $\mathrm{pH}$}

Pengukuran $\mathrm{pH}$ pasta gigi dilakukan secara langsung menggunakan pHmeter (Sulaeman et al, 2005; Sudarmadji et al, 2010)

\section{Pengukuran Kadar Kalsium}

Pengukuran kadar Kalsium (Ca) pada pasta gigi dilakukan secara titrimetric menggunakan EDTA dan indicator EBT (AOAC, 1990; Sulaeman et al, 2005; Sudarmadji et al, 2010).

\section{Pengukuran Daya Sebar}

Pengukuran daya sebar dilakukan dengan menghitung waktu yang ditempuh pasta gigi untuk mencapai batas alas setelah ditindih dengan beban standar (Wadu et al, 2018).

\section{Pengukuran Viscositas}

Pengukuran Viscositas dilakukan secara langsung menggunakan Viscometer sentrifugal (AOAC, 1990; Sudarmadji et al, 2010).

\section{Pengukuran Cemaran Mikroba}

Pengukuran cemaran mikroba pada sediaan pasta gigi dilakukan menggunakan metode tuang permukaan Purnomo, 2014; . Sudarmadji et al, 2010; Wadu et al, 2017) 
Uji Organoleptik Pasta Gigi

Uji tingkat kesukaan (Hedonik) terhadap pasta gigi dilakukan secara Organoleptik Steel \& Torie, 1995; Sandi, 2012)
Hasil karakterisasi fisikokimia sediaan Pasta Gigi berbahan abrasive hidroksiapatit (HAp) ditampilkan pada Tabel 2.

\section{Hasil dan Pembahasan}

Tabel 2. Karakteristik Fisikokimia Sediaan Pasta Gigi Berbahan Abrasive Hidroksiapatit (HAp)

\begin{tabular}{|c|c|c|c|c|c|c|c|c|}
\hline \multirow[t]{2}{*}{ Sampel } & \multirow[t]{2}{*}{$\mathrm{pH}$} & \multirow[t]{2}{*}{$\begin{array}{l}\text { Kalsium } \\
\quad(\%)\end{array}$} & \multirow[t]{2}{*}{$\begin{array}{l}\text { Daya Sebar } \\
(\mathrm{gcm} / \mathrm{s})\end{array}$} & \multicolumn{2}{|c|}{$\begin{array}{l}\text { Viskositas Absolut } \\
\text { (P.a) }\end{array}$} & \multicolumn{3}{|c|}{ Cemaran Mikroba } \\
\hline & & & & $\begin{array}{c}\text { Hari } \\
\text { Pertama }\end{array}$ & $\begin{array}{c}\text { Hari Ke } \\
21\end{array}$ & $\begin{array}{l}\text { Hari } \\
\operatorname{Ke} 7\end{array}$ & $\begin{array}{c}\text { Hari } \\
\text { Ke } 14\end{array}$ & $\begin{array}{c}\text { Hari } \\
\text { Ke } 21\end{array}$ \\
\hline Standar X & 8,5 & - & $\begin{array}{c}1001,01 \pm \\
0,000-\end{array}$ & $25 \pm 0,0$ & $25 \pm 0,0$ & 0,00 & 0,00 & 0,00 \\
\hline Standar Y & 8,9 & - & $\begin{array}{l}1012 \pm \\
0,0000-\end{array}$ & $25,1 \pm 0,0$ & $\begin{array}{c}25,1 \pm \\
0,0 \\
\end{array}$ & 0,00 & 0,00 & 0,00 \\
\hline $\mathrm{CaCO}_{3}$ & 8,3 & $\begin{array}{l}21,10 \pm \\
0,0577 \\
\end{array}$ & $\begin{array}{c}936,37 \pm \\
39,42 \\
\end{array}$ & $25 \pm 0,0$ & $25 \pm 0,0$ & 0,00 & 0,00 & 0,00 \\
\hline $50: 50$ & 8,8 & $\begin{array}{c}27,03 \pm \\
0,0333 \\
\end{array}$ & $\begin{array}{c}931,93 \pm \\
22,62 \\
\end{array}$ & $25 \pm 0,0$ & $27 \pm 0,0$ & 0,00 & 0,00 & 0,00 \\
\hline HAp & 8,9 & $\begin{array}{l}27,67 \pm \\
0,0882 \\
\end{array}$ & $\begin{array}{c}987,33 \pm \\
39,50 \\
\end{array}$ & $25 \pm 0,0$ & $\begin{array}{c}27,5 \pm \\
0,0\end{array}$ & 0,00 & 0,00 & 0,00 \\
\hline SNI & $\begin{array}{l}4,5- \\
10,5 \\
\end{array}$ & - & - & - & - & & $<10^{5}$ & \\
\hline \multirow[t]{2}{*}{ Keterangan } & $\mathrm{X}$ & \multicolumn{7}{|c|}{ Pasta Gigi Dengan Remineralisasi Oleh Mikro Kalsium } \\
\hline & $\frac{\mathrm{Y}}{\mathrm{SNI}}$ & \multicolumn{7}{|c|}{$\begin{array}{c}\text { Pasta Gigi Untuk Gigi Sensitif } \\
\text { SNI } 12-3524-1995\end{array}$} \\
\hline
\end{tabular}

Saat ini bahan aktif dengan kerja ganda sangat dibutuhkan dalam bidang perawatan tubuh (kosmetik) dan juga produk kesehatan (obat-obatan medis) (Purnomo,2014). Kebutuhan bahan aktif dengan kinerja ganda menyebabkan penggagasan HAp sebagai bahan abrasive pada pasta gigi, kandungan HAp juga diharapkan dapat menjadi agen remineralisasi (Wadu et al, 2018) dan juga bahan aktif anibakteri karies (Wadu et al, 2017). HAp dipilih sebagai agen remineralisasi karena diperkirakan memiliki kesamaan struktur dengan struktur kalsium penyusun tulang dan gigi juga diperkirakan dapat menutup lobang berukuran mikro pada permukaan enamel gigi (Wadu et al, 2017; Wadu et al, 2018).

Dilakukan uji tingkat kesukaan terhadap pasta gigi oleh 5 orang panelis yang dipilih secara acak. Tingkat kesukaan diukur menggunakan skor angka 1-5 dengan pembagian tingkat kesukaan Sangat Suka $(\mathrm{SS})=5$, Suka $(\mathrm{S})=4$, Agak Suka $(\mathrm{AS})=3$, Tidak Suka $(\mathrm{TS})=2$, dan Sangat Tidak Suka $(\mathrm{STS})=1$. Diperoleh hasil uji organoleptic yang ditampilkan pada Tabel 3.

Tabel 3. Hasil Uji Organoleptik Pasta Gigi

\begin{tabular}{|c|c|c|c|c|c|}
\hline \multirow[t]{2}{*}{ Panelis } & \multirow[t]{2}{*}{ Parameter } & Pasta Gigi A (HAp) & $\begin{array}{c}\text { Pasta Gigi B (Mix } \\
\text { 50:50 HAp: } \\
\left.\mathrm{CaCO}_{3}\right)\end{array}$ & $\begin{array}{l}\text { Pasta Gigi C } \\
\left(\mathrm{CaCO}_{3}\right)\end{array}$ & Standar \\
\hline & & $\begin{array}{l}\text { Tingkat } \\
\text { Kesukaan }\end{array}$ & $\begin{array}{l}\text { Tingkat } \quad \text { Skor } \\
\text { Kesukaan }\end{array}$ & $\begin{array}{l}\text { Tingkat } \\
\text { Kesukaan }\end{array}$ & $\begin{array}{l}\text { Tingkat } \\
\text { Kesukaan }\end{array}$ \\
\hline
\end{tabular}




\begin{tabular}{|c|c|c|c|c|c|c|c|c|c|}
\hline \multirow[t]{6}{*}{1} & Aroma & $S$ & 4 & $\mathrm{AS}$ & 3 & $S$ & 4 & $S$ & 4 \\
\hline & Rasa & $S$ & 4 & AS & 3 & $S$ & 4 & $S$ & 4 \\
\hline & Tekstur & $\mathrm{S}$ & 4 & $\mathrm{AS}$ & 3 & SS & 5 & $S$ & 4 \\
\hline & Ketampakan & $\mathrm{TS}$ & 2 & $\mathrm{~S}$ & 4 & $\mathrm{~S}$ & 4 & $S$ & 4 \\
\hline & Warna & $\mathrm{S}$ & 4 & $\mathrm{~S}$ & 4 & $\mathrm{~S}$ & 4 & $\mathrm{~S}$ & 4 \\
\hline & $\mathrm{pH}$ & \multicolumn{2}{|c|}{$7,8-8,9$} & \multicolumn{2}{|c|}{$7,8-8,8$} & \multicolumn{2}{|c|}{$7,8-8,3$} & \multicolumn{2}{|c|}{$7,8-8,9$} \\
\hline \multirow[t]{6}{*}{2} & Aroma & AS & 3 & $\mathrm{~S}$ & 4 & $\mathrm{~S}$ & 4 & $\mathrm{~S}$ & 4 \\
\hline & Rasa & AS & 3 & $S$ & 4 & SS & 5 & $S$ & 4 \\
\hline & Tekstur & $\mathrm{S}$ & 4 & AS & 3 & SS & 5 & $\mathrm{SS}$ & 5 \\
\hline & Ketampakan & AS & 3 & $\mathrm{~S}$ & 4 & $\mathrm{~S}$ & 4 & $\mathrm{SS}$ & 5 \\
\hline & Warna & AS & 3 & AS & 3 & $S$ & 4 & SS & 5 \\
\hline & $\mathrm{pH}$ & \multicolumn{2}{|c|}{$7,8-8,9$} & \multicolumn{2}{|c|}{$7,8-8,8$} & \multicolumn{2}{|c|}{$7,8-8,3$} & \multicolumn{2}{|c|}{$7,8-8,9$} \\
\hline \multirow[t]{6}{*}{3} & Aroma & $\mathrm{S}$ & 4 & $\mathrm{AS}$ & 3 & $\mathrm{~S}$ & 4 & SS & 5 \\
\hline & Rasa & $\mathrm{S}$ & 4 & $\mathrm{SS}$ & 5 & $S$ & 4 & SS & 5 \\
\hline & Tekstur & $\mathrm{AS}$ & 3 & SS & 5 & $\mathrm{~S}$ & 4 & SS & 5 \\
\hline & Ketampakan & AS & 3 & $\mathrm{~S}$ & 4 & $\mathrm{~S}$ & 4 & $\mathrm{~S}$ & 4 \\
\hline & Warna & AS & 3 & $\mathrm{SS}$ & 5 & $\mathrm{SS}$ & 5 & $\mathrm{~S}$ & 4 \\
\hline & $\mathrm{pH}$ & \multicolumn{2}{|c|}{$7,8-8,9$} & \multicolumn{2}{|c|}{$7,8-8,8$} & \multicolumn{2}{|c|}{$7,8-8,3$} & \multicolumn{2}{|c|}{$7,8-8,9$} \\
\hline \multirow[t]{6}{*}{4} & Aroma & $\mathrm{SS}$ & 5 & $\mathrm{~S}$ & 4 & $\mathrm{~S}$ & 4 & SS & 5 \\
\hline & Rasa & $\mathrm{S}$ & 4 & $\mathrm{~S}$ & 4 & $\mathrm{~S}$ & 4 & SS & 5 \\
\hline & Tekstur & AS & 3 & $\mathrm{~S}$ & 4 & $\mathrm{SS}$ & 5 & $\mathrm{~S}$ & 4 \\
\hline & Ketampakan & $\mathrm{TS}$ & 2 & $S$ & 4 & $\mathrm{~S}$ & 4 & $S$ & 4 \\
\hline & Warna & AS & 3 & $\mathrm{~S}$ & 4 & $\mathrm{~S}$ & 4 & $\mathrm{~S}$ & 4 \\
\hline & $\mathrm{pH}$ & \multicolumn{2}{|c|}{$7,8-8,9$} & \multicolumn{2}{|c|}{$7,8-8,8$} & \multicolumn{2}{|c|}{$7,8-8,3$} & \multicolumn{2}{|c|}{$7,8-8,9$} \\
\hline \multirow[t]{6}{*}{5} & Aroma & $\mathrm{S}$ & 4 & SS & 5 & SS & 5 & SS & 5 \\
\hline & Rasa & AS & 3 & $\mathrm{SS}$ & 5 & $\mathrm{SS}$ & 5 & $\mathrm{SS}$ & 5 \\
\hline & Tekstur & AS & 3 & $\mathrm{~S}$ & 4 & $\mathrm{SS}$ & 5 & $\mathrm{SS}$ & 5 \\
\hline & Ketampakan & $\mathrm{AS}$ & 3 & $\mathrm{SS}$ & 5 & $\mathrm{SS}$ & 5 & $\mathrm{~S}$ & 4 \\
\hline & Warna & SS & 5 & AS & 3 & $\mathrm{~S}$ & 4 & $\mathrm{~S}$ & 4 \\
\hline & $\mathrm{pH}$ & \multicolumn{2}{|c|}{$7,8-8,9$} & \multicolumn{2}{|c|}{$7,8-8,8$} & \multicolumn{2}{|c|}{$7,8-8,3$} & \multicolumn{2}{|c|}{$7,8-8,9$} \\
\hline
\end{tabular}

Berdasarkan hasil uji organoleptic diperoleh bahwa pasta gigi berbahan abrasive HAp relative disukai oleh panelis, namun untu pasta gigi berbahan aktif campuran HAp dan $\mathrm{CaCO}_{3}$ teksturnya relative agak disukai oleh panelis terlihat dari pilihan panelis yang berada pada kisaran suka ke agak suka. Pasta gigi berbahan abrasive campuran memiliki tekstur agak kasar diakibatkan oleh bercampurnya 2 jenis Kristal kalsium berbeda (baik struktur dan ukuran) menghasilkan struktur Kristal kalsium lain yang kemungkinan ukurannya lebih besar daripada kedua struktur pembentuknya. HAp yang digunakan adalah HAp hasil sintesis yang dipijar pada suhu $900-1000^{\circ} \mathrm{C}$ sehingga kemungkinan ukuran kristalnya berada pada kisaran nanometer, sedangkan $\mathrm{CaCO}_{3}$ yang digunakan adalah $\mathrm{CaCO}_{3}$ yang berderajad PA dengan perkiraan ukuran pada kisaran mikro. Gabungan kedua Kristal akan menghasilkan Kristal lain dengan komposisi penyusun yang sama dengan ukuran berbeda.

Panelis yang dipilih untuk dijadikan panelis uji sebagian besar merupakan perokok, penyuka kopi dan penyuka makanan manis. Kegiatan merokok menyebabkan warna kuning pada permukaan gigi karena menempelnya kompleks $\mathrm{CO}_{x}$ dan $\mathrm{NO}_{\mathrm{x}}$ dari asap rokok sehingga membutuhkan pasta gigi yang mengandung abrasive kuat yang sekaligus dapat meremineralisasi permukaan gigi setelah dibersihkan oleh bahan abrasive. Pembersihan oleh komponen abrasive umumnya juga diikuti tergerusnya mineral pada enamel gigi sehingga perlu mineral sejenis untuk mengganti mineral yang tergerus atau meluruh. 
Kegiatan minum kopi dan makan makanan manis juga dapat menimbulkan masalah pada enamel gigi yaitu pelarutan mineral kalsium akibat suasana asam yang disebabkan oleh gula dan kopi. Nikotin dan glukosa merupakan donor proton yang baik sehingga menyebabkan suasana asam. Suasana asam menyebabkan $\mathrm{Ca}$ terurai menjadi $\mathrm{Ca}^{2+}$ dan permukaan enamel yang kalsiumnya meluruh berpeluang sangat besar sebagai tempat berkembangbiaknya bakteri yang menghasilkan karies. Karies gigi merupakan hasil aktivitas bakteri di permukaan gigi yang dapat merusak struktur dan keindahan gigi karena karies tersusun atas garam natrium rapuh yang bereaksi dan menempel pada permukaan gigi yang kalsiumnya mengalami penguraian. Struktur karies ini sangat rapuh, mengakibatkan pelapukan dan penguraian namun terikat sangat kuat (secara kimiawi) pada permukaan gigi sehingga perlu dibersihkan dan bekasnya perlu di remineralisasi. Penelitian sebelumnya juga telah melaporkan bahwa HAp memiliki daya antibakteri yang kuat terhadap bakteri karies (Wadu et al, 2017).

Masalah - masalah penyebab kerusakan gigi yang diakibatkan kegiatan sehari-hari menyebabkan digagaskannya bahan abrasif berkinerja ganda pada sediaan pasta gigi yaitu sebagai remineralisasi dan juga antibakteri. HAp dipilih sebagai bahan abrasive karena memiliki kesamaan struktur dengan kalsium penyusun enamel gigi juga karena memiliki daya antibakteri yang kuat dan dapat mengurangi aktivitas bakteri penyebab karies.

\section{Kesimpulan}

Pasta gigi berbahan abrasive $\mathrm{CaCO}_{3}$ memiliki kadar kalsium 21,10 $\pm 0,0577 \%$ dengan daya sebar $936,37 \pm 39,42 \mathrm{gcm} / \mathrm{s} ; \mathrm{pH}$ $8,3 \pm 0,00$; dan viscositas $25 \pm 0,00$ P.a. Sementara yang berbahan abrasive 50:50 (HAp: $\mathrm{CaCO}_{3}$ ) memiliki kadar kalsium 27,03 $\pm 0,0333 \%$ dengan daya sebar 931,93 \pm
$22,62 \mathrm{gcm} / \mathrm{s} ; \mathrm{pH} 8,8 \pm 0,00 ;$ dan viscositas 27 $\pm 0,00$ P.a. Sedangkan yang berbahan abrasive HAp memiliki kadar kalsium 27,67 $\pm 0,0882 \%$; daya sebar $987,33 \pm 39,50 \mathrm{gcm} / \mathrm{s}$; pH 8,9 $\pm 0,00$; dan viscositas $27,5 \pm 0,00$ P.a. Tidak ditemukan adanya cemaran mikroba pada semua sediaan pasta gigi selama masa penyimpanan.

Berdasarkan uji organoleptis pasta gigi berbahan abrasive HAp disukai, sementara yang campuran pasta gigi berbahan abrasive HAp: $\mathrm{CaCO}_{3}$ kurang disukai.

\section{Daftar Pustaka}

Association of Official Analytical Chemists. 1990. Official Methods of Analysis $15^{\text {th }}$ Edition. Washington D.C. The United States of America Legally Binding Document.

Burhanuddin, H. 2014. Formulasi dan Uji Stabilitas Fisik Ekstrak Kulit Buah Kakao (Teobroma cacao L.) pada Sediaan Pasta Gigi sebagai Antibakteri terhadap Streptococcus mutans. Prog Studi Farmasi Fakultas Farmasi Universitas Hasanuddin Makassar.

Maldupa, I; Anda, B; Inga, R \& Anna Mahailova. 2012. Evidence Based Toothpaste classification, According to certain Characteristic of their chemical composition. Stomatologija, Baltic Dental and Maxillofacial Journal. 14:12-22, 2012.

Prasetya, R C. 2008. Perbandingan Jumlah Koloni Bakteri Saliva pada AnakAnak Karies dan Non Karies Setelah Mengkonsumsi Minuman Berkarbonasi. Indonesian Journal of Dentistry 2008; 15 (1): 65-70, ISSN: 1693-9697. http://www.fkg.ui.edu .

Pratama, R.N. 2014. Efek Antibakteri Pasta Gigi yang Mengandung Baking Soda dan Pasta Gigi yang Mengandung Fluor Terhadap Pertumbuhan Bakteri Plak. Skripsi. Makassar: Fakultas 
Kedokteran Gigi, Universitas Hasanuddin.

Purnomo, H. 2014, Desain Molekul Antibiotika "Seri Penemuan Obat". Yogyakarta. Pustaka Pelajar. ISBN: 978-602-229-336-1.

Putri, F L; Bertha, R \& Arlina P P. 2015. Analisis Kandungan Flourida pada Sampel Pasta Gigi dari Beberapa Hotel di Kota Bandung Menggunakan Metode Spektrofotometri Sinar Tampak. ISSN: 2460-6472.

Rahman, D A. 2009. Optimasi Sediaan Gel Gigi yang Mengandung Ekstrak Daun Jambu Biji (Psidium guajava L) dengan Na-CMC sebagaiGelling Agent.

Sandi, E O. 2012. Perbedaan Penggunaan Bahan Pengikat Na-CMC dan HPMC Terhadap Sifat Fisik, Kimia dan Uji Hedonik Sediaan Pasta Gigi Enzim Papain Pepaya (Carica papaya L). Surakarta. Universitas Sebelas Maret. Skripsi.

SNI 12-3524-1995. Baku Mutu Sediaan Pasta Gigi.
Steel, R. G, \& Toorie, J. H.1995. Prinsip dan Prosedur Statistika Suatu Pendekatan Biometrik. Gramedia Pustaka. Jakarta.

Sudarmadji, S; Bambang, H; \& Suhardi. 2010. Prosedur Analisa untuk Bahan Makanan dan Pertanian. Yogyakarta. Liberty. ISBN: 979-499-227-5.

Sulaeman; Suparto; \& Evianti. 2005. Analisis Kimia Tanah, Tanaman, Air dan Pupuk. Bogor. Balai Penelitian Tanah Departemen Pertanian.

Wadu, I; Hartati, S; \& Margareta, N C. 2017. Karakterisasi dan Uji Aktivitas Antibakteri Hidroksiapatit (HAp) dari Kerabang Telur Ayam Terhadap Bakteri Lactobacillus acidophilus. JKPK UNS 2017.

Wadu, I; Intan, K R; Agung, R G; \& Sri, H. 2018. Pasta Gigi Pencegah Gigi Berlubang Berbahan Aktif Mikro Hidroksiapatit (HAp) dari Limbah Kerabang Telur Pasar Raya Kota Salatiga. Prosiding Seminar Nasional UNISRI 2018. 